\title{
Immune Complex Transfer Enzyme Immunoassay for Antibodies Using Recombinant Proteins Labeled with 2,4-Dinitrophenyl Group and $\beta$-D-Galactosidase
}

\author{
Eiji Ishikawa \\ Department of Biochemistry, Miyazaki Medical College, Kiyotake, Miyazaki 889-16
}

Received for publication January 27, 1997

Ultrasensitive enzyme immunoassays limmune complex transfer enzyme immunoassays) were developed for antibody IgGs. Antibody IgGs were reacted with 2,4dinitrophenyl-antigen and antigen- $\beta$-D-galactosidase conjugate, and the immune complexes comprising the three components were trapped onto solid phase coated with (anti-2,4-dinitrophenyl group) IgG and were transferred to solid phase coated with lantihuman $\operatorname{lgG} \gamma$-chain) $\lg G$ in the presence of $\varepsilon N$-2,4-dinitrophenyl-L-lysine. These immunoassays were much more sensitive and specific than currently available conventional methods and were applied for detection of antibody IgGs to HIV-1. Diagnosis and confirmation of HIV-1 infection using urine, whole saliva and serum samples became more reliable with less indeterminate results. And the window period in diagnosis of HIV-1 infection, during which diagnosis of HIV-1 infection is not possible due to the absence of detectable antibodies to HIV-1, was shortened by approximately two weeks with the immune complex transfer enzyme immunoassay for simultaneous detection of p24 antigen of HIV-1 and antibody IgGs to p17 antigen and reverse transcriptase of HIV-1 in a single assay tube. Furthermore, it has recently become possible to perform the immune complex transfer enzyme immunoassay within 2 to $3 \mathrm{hr}$ with higher sensitivity and, as a result, to further shorten the window period in diagnosis of HIV-1 infection.

Key words: Enzyme immunoassay, Antigen, Antibody, $\beta$-D-galactosidase, Human immunodeficiency virus type 1, Reverse transcriptase, P17, P24

\section{Introduction}

For the last two decades, the conventional enzymelinked immunosorbent assay (ELISA) for antibodies in body fluids has been used successfully to aid diagnosis of autoimmune diseases and infections. For example, ELISA is one of the most widely used methods to detect antibodies to human immunodeficiency virus (HIV) and human T-cell leukemia virus (HTLV) for diagnosis of HIV

Correspondence to: Eiji Ishikawa, M.D., Ph.D., Professor of Biochemistry, Department of Biochemistry, Miyazaki Medical College, Kiyotake, Miyazaki 889-16, Japan.

Selected by "The 10th International Congress of Histochemistry and Cytochemistry" held in Kyoto, Japan on Aug. 18-23, 1996. and HTLV infections [1]. However, the conventional ELISA is not sufficiently sensitive for some purposes. Relevant autoantibodies are not demonstrated in all patients with autoimmune diseases. Higher sensitivity is recommended to narrow a window period after HIV infection, during which diagnosis of HIV infection is not possible due to the absence of detectable antibodies to HIV. Higher sensitivity is required to detect antibodies in body fluids such as urine and saliva containing much lower concentrations of immunoglobulins than serum/plasma. This article reviews the principle and applications of recently developed ultrasensitive enzyme immunoassay (immune complex transfer enzyme immunoassay) for antibodies in body fluids with emphasis on diagnosis of HIV-1 infection. 


\section{Principle and Sensitivity of Immune Complex Transfer Enzyme Immunoassay}

In the most widely used conventional ELISA, antigen-coated solid phase is reacted with antibodies in samples and, after washing, with anti-immunoglobulin antibody-enzyme conjugate. Enzyme activity bound to the solid phase is correlated to the amount of antibodies to be measured. The sensitivity of this assay is seriously limited by the nonspecific binding of the conjugate to the solid phase, which is caused probably by the nonspecific binding of nonspecific immunoglobulins and other substance(s) in the samples. This drawback has been overcome by a method to transfer the immune complex of labelled antigen and antibodies to be measured from one solid phase to another, eliminating nonspecific immunoglobulins and other interfering substance(s) (immune complex transfer enzyme immunoassay) $[9,11]$.

In the initially developed method, antibodies to be measured are reacted with 2,4-dinitrophenyl-biotinyl-antigen, and the immune complex formed is trapped onto solid phase coated with (anti-2,4-dinitrophenyl group) IgG (the first solid phase). After washing, the immune complex is eluted from the first solid phase with excess of $\varepsilon N$ 2,4-dinitrophenyl-L-lysine and is transferred onto solid phase coated with avidin (the second solid phase). Nonspecific immunoglobulins and other interfering substance(s) are minimized by transfer of the immune complex from the first solid phase to the second one. The immune complex on the second solid phase is reacted with (anti-immunoglobulin) antibody Fab'-enzyme conjugate, and the enzyme activity bound to the second solid phase is correlated to the amount of antibodies to be measured. This original method has been modified in various ways.

In the most successful immune complex transfer enzyme immunoassay (Fig. 1), antibodies to be measured are reacted simultaneously with 2,4-dinitrophenyl-antigen and antigen-enzyme conjugate. The immune complex formed, comprising the three components, is trapped onto solid phase coated with (anti-2,4-dinitrophenyl group) IgG. After washing, the immune complex is eluted from the solid phase with excess of $\varepsilon N$-2,4-dinitrophenyl-L-lysine and was transferred to solid phase coated with anti-immunoglobulin IgG. The sensitivity depends on the detection limit of enzymes as label. The use of $\beta$-D-galactosidase from Escherichia coli improves the sensitivity approximately 10-fold as compared with that of horseradish peroxidase. The sensitivity for anti-insulin IgG and anti-thyroglobulin IgG using $\beta$-D-galactosidase from Escherichia coli as label was 2,000 to 4,000 -fold higher than that of the corresponding conventional ELISA.

The concentrations of IgG in urine and whole saliva samples of healthy subjects are $3.8 \pm 4.7$ (SD) $\mu \mathrm{g} / \mathrm{ml}$ (range, $0.05-41 \mu \mathrm{g} / \mathrm{ml}$ ) [7] and $35 \pm 36$ (SD) $\mu \mathrm{g} / \mathrm{ml}$ (range, $0.7-187 \mu \mathrm{g} / \mathrm{ml}$ ) [14], respectively. These are approximately 4,000-fold and 400-fold, respectively, lower than those in serum samples $(15.2 \pm 6.3(\mathrm{SD}) \mathrm{mg} / \mathrm{ml}$; range, 3.8-
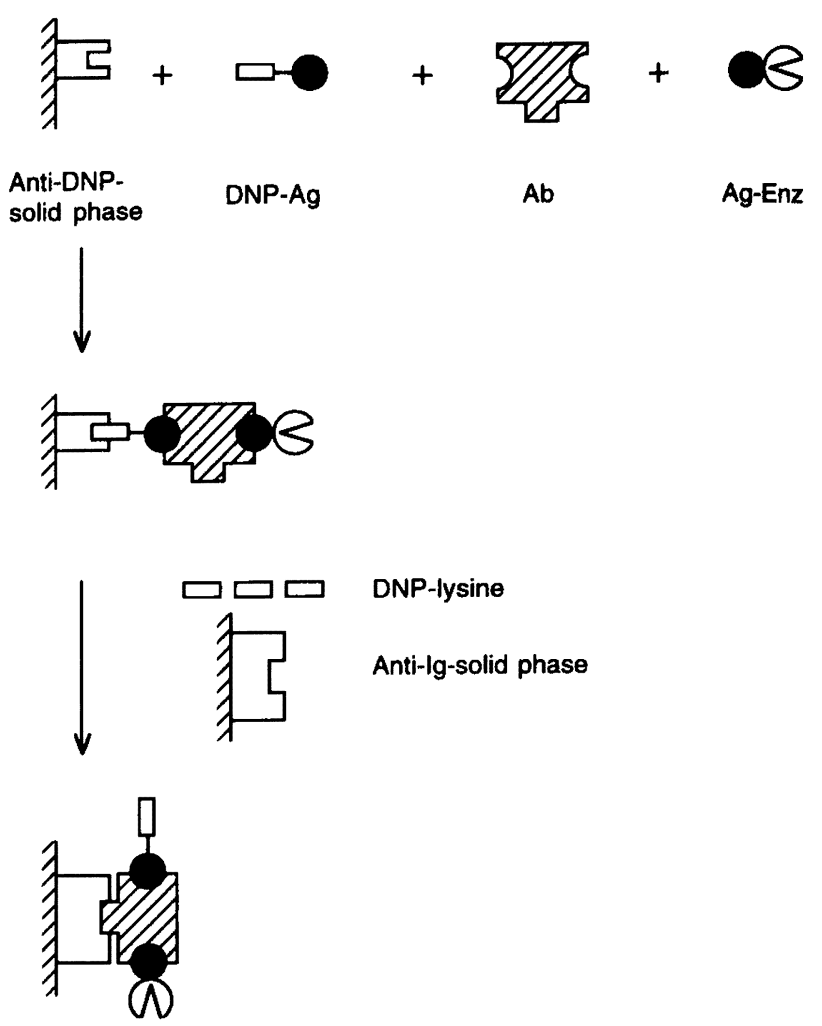

Fig. 1. Immune complex transfer enzyme immunoassay for antibody IgG. DNP: 2,4-dinitrophenyl group, Ag: antigen, $\mathrm{Ab}$ : antibody, Enz: enzyme, Ig: immunoglobulin.

$36 \mathrm{mg} / \mathrm{ml}$ ) [7]. Therefore, an ultrasensitive method such as the immune complex transfer enzyme immunoassay is required for the detection of antibody IgG to HIV-1 in urine and whole saliva samples.

Diagnosis of HIV infection by detection of antibodies to HIV is possible only after a window period following the infection, during which no antibodies to HIV is detectable. In order to shorten the window period for avoiding accidental HIV infection by blood transfusion and organ transplantation, use of an ultrasensitive method is essential.

\section{Diagnosis of HIV-1 Infection with Urine}

\section{Sensitivity and specificity}

Eighty three urine samples from HIV-1 seropositive subjects (60 asymptomatic carriers, 11 patients with AIDSrelated complex (ARC) and 12 patients with AIDS) and 100 urine samples from $\mathrm{HIV}-1$ seronegative subjects were tested by the immune complex transfer enzyme immunoassay using recombinant reverse transcriptase (rRT) as antigen and $\beta$-D-galactosidase from Escherichia coli as label (Fig. 2) [7]. The volume of urine samples used was $100 \mu$. The ratios of the lowest signals for the asymptomatic carriers and the patients with ARC and AIDS to the highest signal for the seronegative subjects were 8.2,11 and 7.2 , respectively, when bound $\beta$-D-galactosidase activi- 


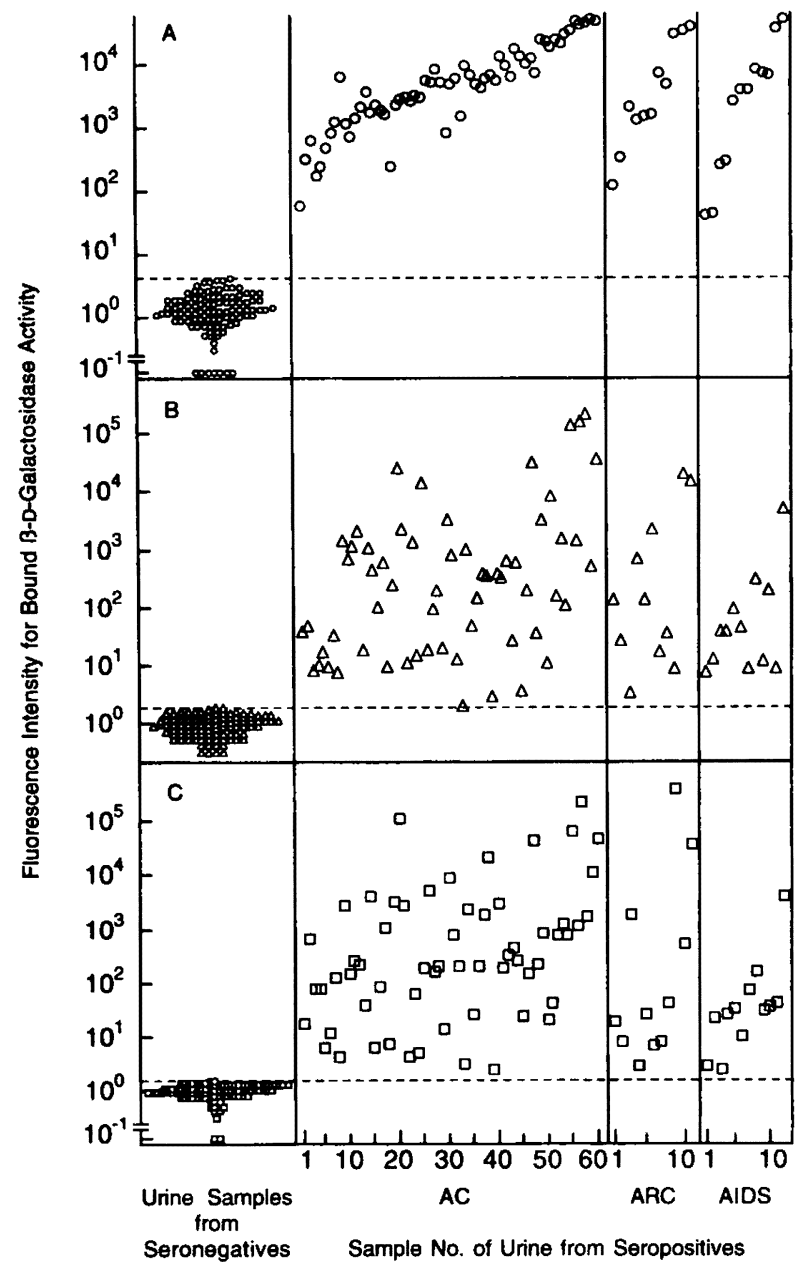

Fig. 2. Detection of antibody IgG to HIV-1 in unconcentrated urine samples. Urine samples from 83 HIV-1 seropositive subjects (60 asymptomatic carriers, 11 patients with ARC and 12 patients with AIDS) and 100 HIV-1 seronegative subjects were tested by the immune complex transfer enzyme immunoassays using rRT (A, circles), rp17 (B, triangles) and rp24 (C, squares) as antigens and $\beta$-D-galactosidase from Escherichia coli as label. The volume of urine samples used was $100 \mu \mathrm{l}$. Bound $\beta$-D-galactosidase activity was assayed at $30^{\circ} \mathrm{C}$ for $25 \mathrm{hr}$. The broken lines indicate the highest signals for the seronegative subjects. AC: asymptomatic carriers, ARC: patients with AIDS-related complex, AIDS: patients with AIDS.

ty was assayed for $2.5 \mathrm{hr}$. By a longer assay $(25 \mathrm{hr})$ of bound $\beta$-D-galactosidase activity, the ratios were enhanced to 14,29 , and 10 , respectively (Fig. $2 \mathrm{~A}$ ). The ratios were also significantly enhanced by using approximately 10-fold concentrated urine samples, which can be prepared by 20 min centrifugation in a microconcentrator and by the combined use of rRT, recombinant p17 (rp17) and recombinant p24 (rp24), since signals with $\mathrm{rRT}$ as antigen were lower than those with $\mathrm{rp} 17$ or/and rp24 as antigens in some HIV-1 seropositive subjects.

Thus, the sensitivity and the specificity of the immune complex transfer enzyme immunoassay for antibody IgG to HIV- 1 in urine using rRT as antigen and $\beta$-D-galac- tosidase from Escherichia coli as label were both $100 \%$ (sensitivity: 60/60 for asymptomatic carriers, 11/11 for patients with ARC and 12/12 for patients with AIDS and specificity: 100/100) with no indeterminate results using $100 \mu 1$ of unconcentrated urine samples (Fig. 2) and were expected to be both $100 \%$ even for a larger number of samples by using both 10 -fold concentrated urine samples and the three antigens (rRT, rp17 and rp24). Furthermore, the positivity could be confirmed by separately demonstrating antibody $\operatorname{IgG}$ to each of $\mathrm{rRT}, \mathrm{rp} 17$ and rp24 in most cases [7] (Fig. 2). However, it is recommended to measure IgG in each urine sample and not to make negative diagnosis for urine samples containing less than $1 \mu \mathrm{g} / \mathrm{ml}$ of $\mathrm{IgG}$.

\section{Correlation to serum}

Twenty five paired urine $(\mathrm{Y})$ and serum $(\mathrm{X})$ samples from 17 asymptomatic carriers, 3 patients with ARC and 5 patients with AIDS were tested by the immune complex transfer enzyme immunoassays using rRT, rp17 and rp24 as antigens and $\beta$-D-galactosidase from Escherichia coli as label. When signals were corrected by the amount of IgG, the regression equations and the correlation coefficients were $\log (Y)=1.0 \log (X)-1.6$ and $r=0.66$ with $r R T$, $\log (Y)=0.73 \log (X)-0.64$ and $r=0.79$ with $\mathrm{rp} 17$ and $\log (Y)=0.82 \log (X)-0.51$ and $r=0.87$ with $r p 24$. The specific activity of antibody IgG to RT of HIV-1 (the signal corrected by the amount of $\mathrm{IgG}$ ) in urine samples was 3.9 to 34 -fold lower in $56 \%$ of the 25 samples than that in serum samples, 50 to 115 -fold lower in $32 \%$ and 213 to 979-fold lower in $12 \%$. The specific activity of antibody IgG to p17 and p24 was also lower in urine samples than in serum samples, although to less degrees. These results suggested that antibody IgGs to HIV-1 were inactivated to various degrees in the kidney but not drastically in urine samples collected, since antibody IgG to HIV-1 RT was stable at $-20^{\circ} \mathrm{C}$ for 6 months as described above and after several freezing-thawings.

\section{Diagnosis of HIV-1 Infection with Whole Saliva}

\section{Sensitivity and specificity}

Whole saliva samples were collected from 63 HIV-1 seropositive subjects ( 45 asymptomatic carriers, 8 patients with ARC and 10 patients with AIDS) and 76 medical students ( 50 males and 26 females) and were tested by the immune complex transfer enzyme immunoassay using rRT as antigen and $\beta$-D-galactosidase from Escherichia coli as label (Fig. 3) [14]. Using as little as one microliter of whole saliva samples, the ratios of the lowest signals for the asymptomatic carriers and the patients with ARC and AIDS to the highest signal for the medical students were 38,78 and 3 , respectively.

When the volume of whole saliva for test was increased up to $100 \mu$, signals for HIV-1 seropositive subjects increased proportionally, while signals for the medical 


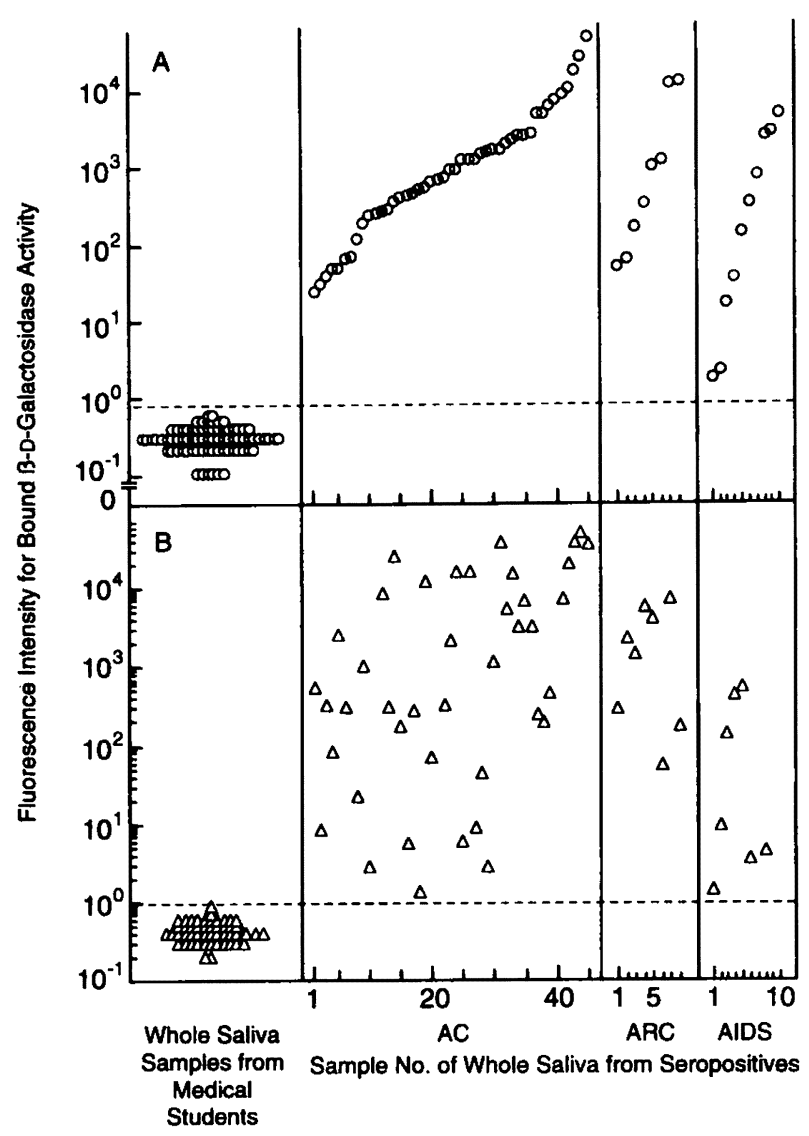

Fig. 3. Detection of antibody IgG to HIV-1 in whole saliva samples. One $\mu \mathrm{l}$ of whole saliva samples from 63 HIV-1 seropositive subjects (45 asymptomatic carriers, 8 patients with ARC and 10 patients with AIDS) and 76 medical students were tested by the immune complex transfer enzyme immunoassays using $\mathrm{rRT}$ ( $\mathrm{A}$, circles) and $\mathrm{rp} 17$ (B, triangles) as antigens and $\beta$-Dgalactosidase from Escherichia coli as label. Bound $\beta$-D-galactosidase activity was assayed at $30^{\circ} \mathrm{C}$ for $2.5 \mathrm{hr}$. The broken lines indicates the highest signals for the medical students.

students increased only slightly [14]. Therefore, whole saliva samples containing extremely low levels of antibody IgG to RT of HIV-1, even 2,000-fold lower than the lowest level among the asymptomatic carriers and the patients with ARC and 150-fold lower than the lowest level among the patients with AIDS, were considered to be discriminated from those of HIV-1 seronegative subjects. Positive results with $\mathrm{rRT}$ as antigen can be confirmed by demonstrating antibody IgG to rp17 and probably rp24 in most of whole saliva samples. Although 34 subjects out of the 63 seropositive subjects were hemophiliacs, the concentrations of IgG in whole saliva samples from the hemophiliacs and the nonhemophiliacs were not very different, indicating that the above results were not due to bleeding in the oral cavity of the hemophiliacs, if any [14].

Thus, the sensitivity and the specificity of the immune complex transfer enzyme immunoassay for antibody IgG to HIV-1 in whole saliva samples using $\mathrm{RTT}$ as antigen and $\beta$-D-galactosidase from Escherichia coli as label were both
100\% (sensitivity: $45 / 45$ for asymptomatic carriers, $8 / 8$ for patients with ARC and 10/10 for patients with AIDS and specificity: 76/76) with no indeterminate results using as little as one microliter of whole saliva samples (Fig. 3) and were expected to remain both $100 \%$ even for a larger number of samples by increasing the volume of whole saliva samples up to $100 \mu \mathrm{l}$, if necessary. However, it is recommended to measure IgG in each whole saliva sample and not to make negative diagnosis for whole saliva samples containing less than $10 \mu \mathrm{g} / \mathrm{ml}$.

\section{Correlation to serum}

Paired samples of whole saliva (Y) and serum (X) from 30 to 34 HIV-1 seropositive subjects (22-24 asymptomatic carriers, 4 patients with ARC and 4-6 patients with AIDS) were tested by the immune complex transfer enzyme immunoassays using rRT and rp17 as antigens and $\beta$-D-galactosidase from Escherichia coli as label [14]. The regression equations and the correlation coefficients were $\log (\mathrm{Y})=0.98 \log (\mathrm{X})-0.19$ and $\mathrm{r}=0.92$ with $\mathrm{rRT}$ as antigen and $\log (Y)=0.78 \log (X)+0.55$ and $r=0.95$ with rp17 as antigen, when signals were corrected by the amount of IgG.

\section{Diagnosis with dried whole saliva}

The diagnosis of HIV-1 infection in asymptomatic carriers has been shown to be possible using even dried whole saliva samples (2-3 $\mu$ l) on filter paper discs with a diameter of $3 \mathrm{~mm}$ as a substitute for frozen ones [16].

\section{Diagnosis of HIV-1 Infection with Serum}

\section{Sensitivity}

Serum samples from 79 HIV-1 seropositive subjects (50 asymptomatic carriers, 9 patients with AIDS-related complex (ARC) and 20 patients with AIDS) and 100 HIV-1 seronegative subjects were tested by the immune complex transfer enzyme immunoassays (Fig. 4) [8]. The volume of serum samples used was $10 \mu \mathrm{l}$. The ratios of the lowest signals with $\mathrm{rRT}$ as antigen for the asymptomatic carriers and the patients with ARC and AIDS to the highest signal for the seronegative subjects were $56,000,66,000$ and 5,200 , respectively. Even with $1 \mu \mathrm{l}$ of serum samples, the ratios were $22,400,26,400$ and 2,080 , respectively, since the highest signal for the seronegative subjects was lowered by reducing the volume of serum samples used [14]. Using $10 \mu \mathrm{l}$ of serum samples, the ratios with $\mathrm{rp} 17$ as antigen for the asymptomatic carriers and the patients with ARC were 680 and 1,200 , respectively, and the ratios with rp24 as antigen for the asymptomatic carriers and the patients with ARC were 22 and 89 , respectively. In the patients with AIDS, however, one serum sample was negative with rp17 as antigen, and two serum samples were negative with rp24 as antigen.

Thus, the sensitivity of the immune complex transfer enzyme immunoassay using each of the three antigens was $100 \%$ for the asymptomatic carriers $(50 / 50)$ and the 


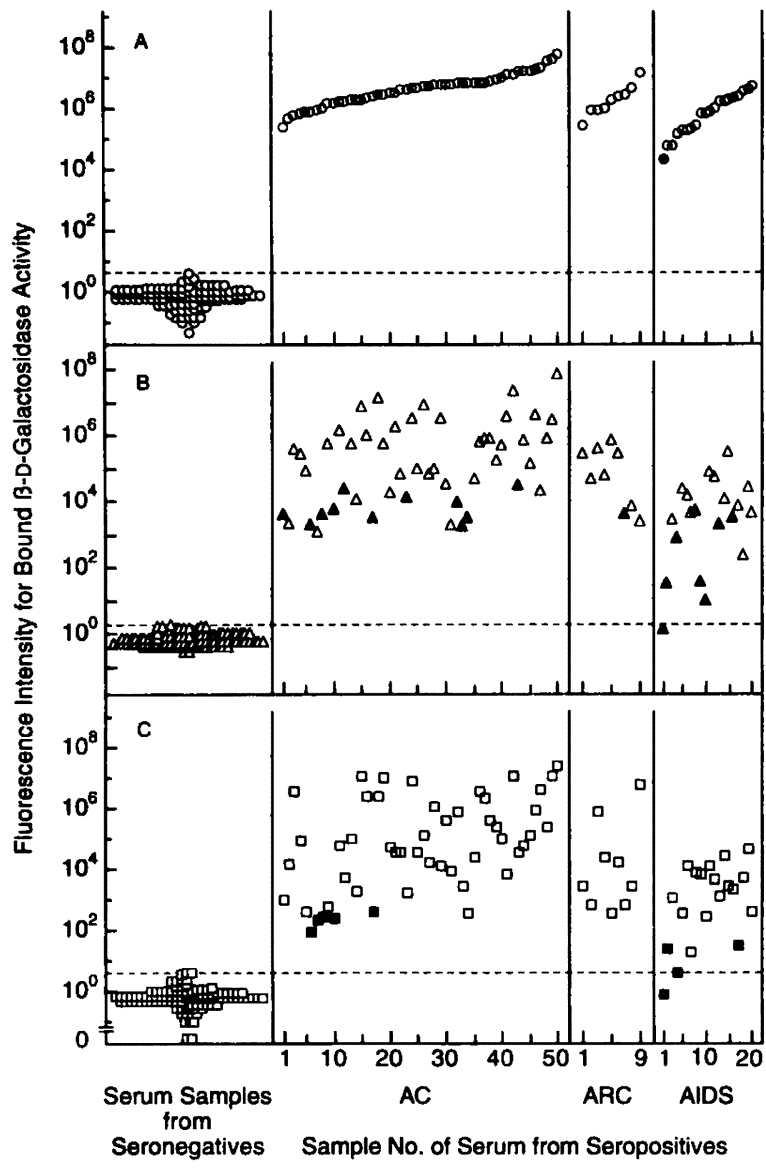

Fig. 4. Detection of antibody IgG to HIV-1 in serum samples. Serum samples $(10 \mu \mathrm{l})$ from $79 \mathrm{HIV}-1$ seropositive subjects (50 asymptomatic carriers, 9 patients with ARC and 20 patients with AIDS) and $100 \mathrm{HIV}-1$ seronegative subjects were tested by the immune complex transfer enzyme immunoassays using rRT (A, circles), rp17 (B, triangles) and rp24 (C, squares) as antigens and $\beta$-D-galactosidase from Escherichia coli as label. Bound $\beta$-D-galactosidase activity was assayed at $30^{\circ} \mathrm{C}$ for $2.5 \mathrm{hr}$. Open and closed symbols indicate serum samples tested positive and negative, respectively, by Western blotting for the corresponding antigens. The broken lines indicate the highest signals among the 100 seronegative subjects, which were taken as tentative cut-off values.

patients with ARC (9/9). For the patients with AIDS, the sensitivities were $100 \%$ with rRT (20/20), $95 \%$ with rp 17 $(19 / 20)$ and $90 \%$ with rp24 (18/20). By contrast, the sensitivities of Western blotting (Ortho Diagnostic Systems Inc., Raritan, NJ) were lower (Fig. 4). The sensitivities of Western blotting for p66 (one of RT components), p51 (the other component of RT), p17 and p24 bands were $100 \%(50 / 50), 100 \%(50 / 50), 78 \%(39 / 50)$ and $90 \%$ $(45 / 50)$, respectively, in the asymptomatic carriers, $100 \%$ (9/9), $100 \%(9 / 9), 89 \%(8 / 9)$ and $100 \%(9 / 9)$, respectively, in the patients with ARC and 95\% (19/20), 75\% $(15 / 20), 60 \%(12 / 20)$ and $80 \%(16 / 20)$, respectively, in the patients with AIDS.

The sensitivities with $10 \mu \mathrm{l}$ of serum samples of the immune complex transfer enzyme immunoassays using rRT, rp17 and rp24 as antigens and $\beta$-D-galactosidase from Escherichia coli as label were more directly compared with those of other methods by testing low levels of antibodies to HIV-1. Two serum samples from HIV-1 seropositive subjects were serially diluted with serum from an HIV-1 seronegative subject and were tested by the immune complex transfer enzyme immunoassays, Western blotting (Ortho kit), the conventional ELISA using five recombinant proteins of HIV-1 as antigens (Abbott HTLV-III EIA kit) and the gelatin particle agglutination test using a lysate of HIV-1 as antigen (Serodia-HIV kit, Fujirebio Inc.) [8]. The maximal dilutions of the serum samples to show the positivity were compared. Tentative cut-off values in the immune complex transfer enzyme immunoassays and the conventional ELISA were the highest signals among 100 HIV-1 seronegative subjects and 75 HIV-1 seronegative subjects, respectively. The immune complex transfer enzyme immunoassays using rRT, rp17 and rp24 were 300 to 1,000 -fold, 1,000 to 3,000 -fold and 30 to 100 -fold, respectively, more sensitive than Western blottings for the corresponding antigens (p66 as one component of RT, p17 and p24) and 10 to 300 -fold more sensitive than the conventional ELISA and the gelatin particle agglutination test, as far as the serum samples tested were concerned. Western blotting for the other component of RT, p51, was less sensitive than that for $\mathrm{p} 66$. Similar results were obtained with Sanofi kit.

\section{Specificity}

The specificity of the immune complex transfer enzyme immunoassay using each of the three antigens (rRT, rp17 and rp24) was $100 \%(100 / 100)$ as shown in Fig. 4 but was further tested as follows.

Thirty two serum samples containing rheumatoid factor (13 samples) and autoantibodies to thyroglobulin (6 samples), DNA (10 samples) and acetylcholine receptor (3 samples) from HIV-1 seronegative subjects were tested by the immune complex transfer enzyme immunoassay using each of the three antigens (rRT, rp17 and rp24) [8]. The concentration of $\mathrm{IgG}$ in these serum samples was $21 \pm 9.2$ (SD) $\mathrm{mg} / \mathrm{ml}$ (range, $7.5-59 \mathrm{mg} / \mathrm{ml}$ ), and levels of autoantibodies to thyroglobulin in three serum samples out of the 32 and to DNA in one serum sample were too high to be quantified without dilution. All the serum samples showed lower signals than the highest signals for the $100 \mathrm{HIV}-1$ seronegative subjects shown in Fig. 4. In addition, there was only very weak correlation between the signal and the concentration of IgG in serum $(r=0.37$ with $r R T, r=0.64$ with $\mathrm{rp} 24$ and $\mathrm{r}=0.30$ with $\mathrm{rp} 17$ ), and little correlation was observed between signals with two antigens out of the three $(r=0.02$ between signals with $r R T$ and $r p 17, r=0.08$ between signals with $r R T$ and $r p 24$ and $r=0.24$ between signals with rp17 and rp24). These results indicated that the concentration of immunoglobulins in serum samples was not a major cause for higher signals among seronegative samples but that a cause(s) for higher signals among seronegative samples was different among the three 
antigens.

\section{Test of seroconversion serum panels}

Eleven HIV-1 seroconversion serum panels (SV-0111, SV-0161, SV-0051, SV-0211 and SV-0241 from North American Biologicals, Miami, FL and Panel P, Panel Z, Panel E, Panel J, Panel S and Panel K from Boston Biomedica, West Bridgewater, MA) were tested by the immune complex transfer enzyme immunoassay using each of $\mathrm{rRT}, \mathrm{rp} 17$ and $\mathrm{rp} 24$ as antigen, and the results were compared with those by the 3rd generation enzyme immunoassay using recombinant gp41 and p24 as antigens (Abbott Laboratories, North Chicago, IL) and the gelatin particle agglutination test using a lysate of HIV-1 as antigen (Fujirebio Inc., Tokyo, Japan) [6]. In 9 seroconversion serum panels out of the 11, antibody IgGs to p17, p24 and RT were detected by the immune complex transfer enzyme immunoassays as early as or even earlier than antibodies to HIV-1 by the other methods. In one of the 11 , antibody IgG to p17 was detected by the immune complex transfer enzyme immunoassay as early as antibodies to HIV-1 by the other methods, but antibody IgGs to p 24 and RT were detected later. In another panel, the detection of antibody IgG to p17 by the immune complex transfer enzyme immunoassay was as early as the detection of antibodies to HIV-1 by the gelatin particle agglutination test but was later than the detection of antibodies to HIV-1 by the 3rd generation enzyme immunoassay and the detection of antibody IgGs to p24 and RT by the immune complex transfer enzyme immunoassay was later.

\section{Detection of p24 Antigen in Serum}

\section{Sensitivity and specificity}

An ultrasensitive immunoassay (two-site immune complex transfer enzyme immunoassay) for p24 antigen of HIV-1 has been developed by applying the same principle as used for the detection of antibodies as shown in Fig. 5 [5]. The antigen was reacted simultaneously with 2,4dinitrophenyl-biotinyl-bovine serum albumin-anti-rp24 Fab' conjugate and anti-rp24 Fab'- $\beta$-D-galactosidase conjugate. The complex formed, comprising the three components, was trapped onto polystyrene beads coated with affinity-purified (anti-2,4-dinitrophenyl group) IgG. The polystyrene beads were washed to eliminate excess of anti-rp24 Fab'- $\beta$-D-galactosidase conjugate. The complex was eluted from the polystyrene beads with excess of

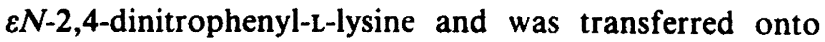
polystyrene beads coated with streptavidin to eliminate nonspecifically bound anti-rp24 Fab'- $\beta$-D-galactosidase conjugate more completely. $\beta$-D-Galactosidase activity bound to the last beads was assayed by fluorometry.

The detection limit of rp24 per assay is 0.1 amol $(2.4$ fg) and 30-fold smaller than that by the conventional twosite enzyme immunoassay using polystyrene beads coated with anti-rp24 IgG and anti-rp24 Fab'- $\beta$-D-galactosidase conjugate. The assay range of p24 in serum is 0.24
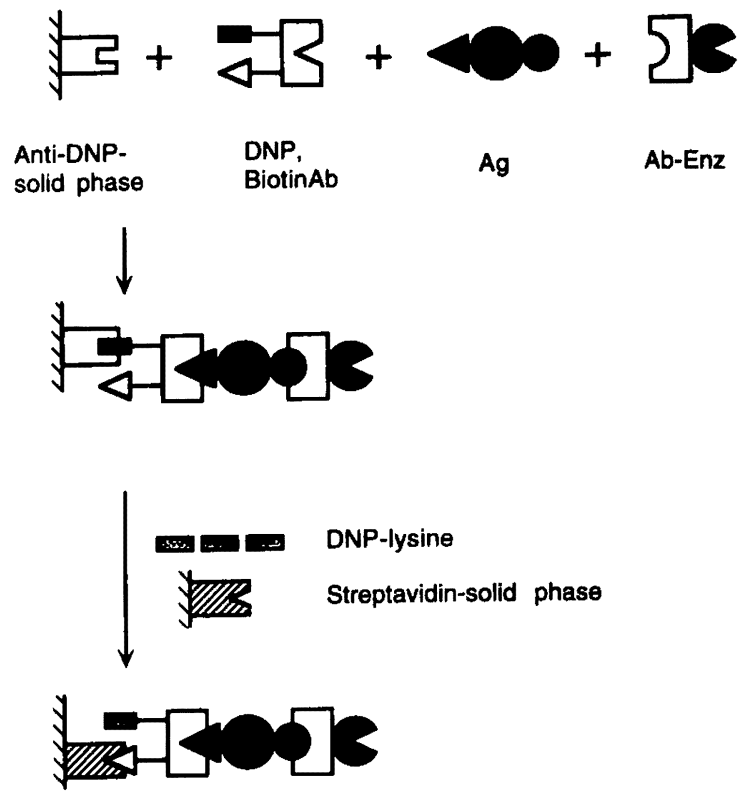

Fig. 5. Immune complex transfer enzyme immunoassay for antigen. DNP: 2,4-dinitrophenyl group, $\mathrm{Ab}$ : antibody, $\mathrm{Ag}$ : antigen, Enz: enzyme.

$720 \mathrm{pg} / \mathrm{ml}$, since the signal increased linearly with up to $7.2 \mathrm{pg} /$ tube and $10 \mu \mathrm{l}$ of serum can be used without serum interference [5].

Serum samples were collected from 79 HIV-1 seropositive subjects (50 asymptomatic carriers, 9 patients with AIDS-related complex (ARC) and 20 patients with AIDS) and $117 \mathrm{HIV}-1$ seronegative subjects.

Without acid-treatment of serum samples, p24 antigen was detected in 24 serum samples (48\%) out of 50 from the asymptomatic carriers, 7 serum samples (78\%) out of 9 from the patients with ARC, 18 serum samples (90\%) out of 20 from the patients with AIDS and 6 serum samples (5\%) out of 117 from the seronegative subjects.

When serum samples were treated at low $\mathrm{pH}$ to inactivate antibodies to HIV-1 p24 antigen with less impairment of p24 immunoreactivity, serum p24 levels were enhanced 1.4 to 17.4 -fold in 19 serum samples (1.4 to 2.0fold in 5 and more than 2.0-fold in 14) out of 50 serum samples from the asymptomatic carriers, 1.3 to 24 -fold in 6 serum samples (1.3-fold in one and more than 2.0-fold in 5) out of 9 serum samples from the patients with ARC and 1.4 to 30.7 -fold in 11 serum samples (1.4 to 2.0 -fold in 3 and more than 2.0 -fold in 8 ) out of 20 serum samples from the patients with AIDS. As a result, p24 antigen was detected in 34 serum samples $(68 \%)$ out of 50 from the asymptomatic carriers, in 7 serum samples (78\%) out of 9 from the patients with ARC, in 18 serum samples (90\%) out of 20 from the patients with AIDS and in none of 117 serum samples from the seronegative subjects.

Thus, the specificity of the immune complex transfer enzyme immunoassay for p24 antigen in serum samples was $95 \%$ without acid-treatment of serum but was improv- 
ed to $100 \%$ by acid-treatment. Recently, the specificity even without acid-treatment of serum has been improved to $100 \%$ by substituting monoclonal mouse anti-p24 Fab'$\beta$-D-galactosidase conjugate for rabbit anti-p24 Fab'- $\beta$-Dgalactosidase conjugate [4]. The sensitivity for the asymptomatic carriers was $48 \%$ without acid-treatment and was improved to $68 \%$ by acid-treatment. The sensitivities for the patients with ARC and AIDS were $78 \%$ and $90 \%$, respectively, regardless of acid-treatment, although serum p24 levels in 55-67\% of the samples were significantly enhanced by acid-treatment as described above.

\section{Test of seroconversion serum panels}

Serum samples of eleven HIV-1 seroconversion serum panels tested by the immune complex transfer enzyme immunoassays for antibody IgGs to p17, p24 and RT of HIV-1 and other methods as described above, were subjected to the immune complex transfer enzyme immunoassay for p24 antigen using monoclonal mouse antip24 Fab'- $\beta$-D-galactosidase conjugate [6]. In ten panels out of the 11, signals for p24 antigen became positive 6 to 42 days earlier than those by the conventional ELISA, the gelatin particle agglutination test and Western blotting for antibodies to HIV-1, but declined as levels of antibody IgG or antibodies to HIV-1 rose. In one panel, p24 antigen was not detected.

\section{Shortening of the Window Period}

\section{Choice of antigens}

The results described above for urine, whole saliva and serum samples have indicated advantages of using $\mathrm{rRT}$ or rp66 of HIV-1 as antigen over other antigens for detection of antibodies to HIV-1 in HIV-1 seropositive subjects. However, it should be noted that signals by the immune complex transfer enzyme immunoassay with $\mathrm{rRT}$ as antigen were lower than those with p17 as antigen in most of HIV-1 seroconversion serum panels tested [6].

The disadvantage of using rRT as antigen described above can be overcome by using rp17 as antigen. In most of HIV-1 seroconversion serum panels tested, signals by the immune complex transfer enzyme immunoassay using rp17 as antigen were higher than those using rRT and rp24 as antigens, and antibody IgG to p17 was detected as early as or even earlier than not only antibody IgGs to RT and p24 by the immune complex transfer enzyme immunoassay but also antibody IgG or antibodies to HIV-1 by the conventional ELISA and the gelatin particle agglutination test [6].

Thus, the seropositivity of HIV-1 infected subjects can be detected from early stages through late stages of the infection by the immune complex transfer enzyme immunoassay using both rRT and rp17 as antigens.

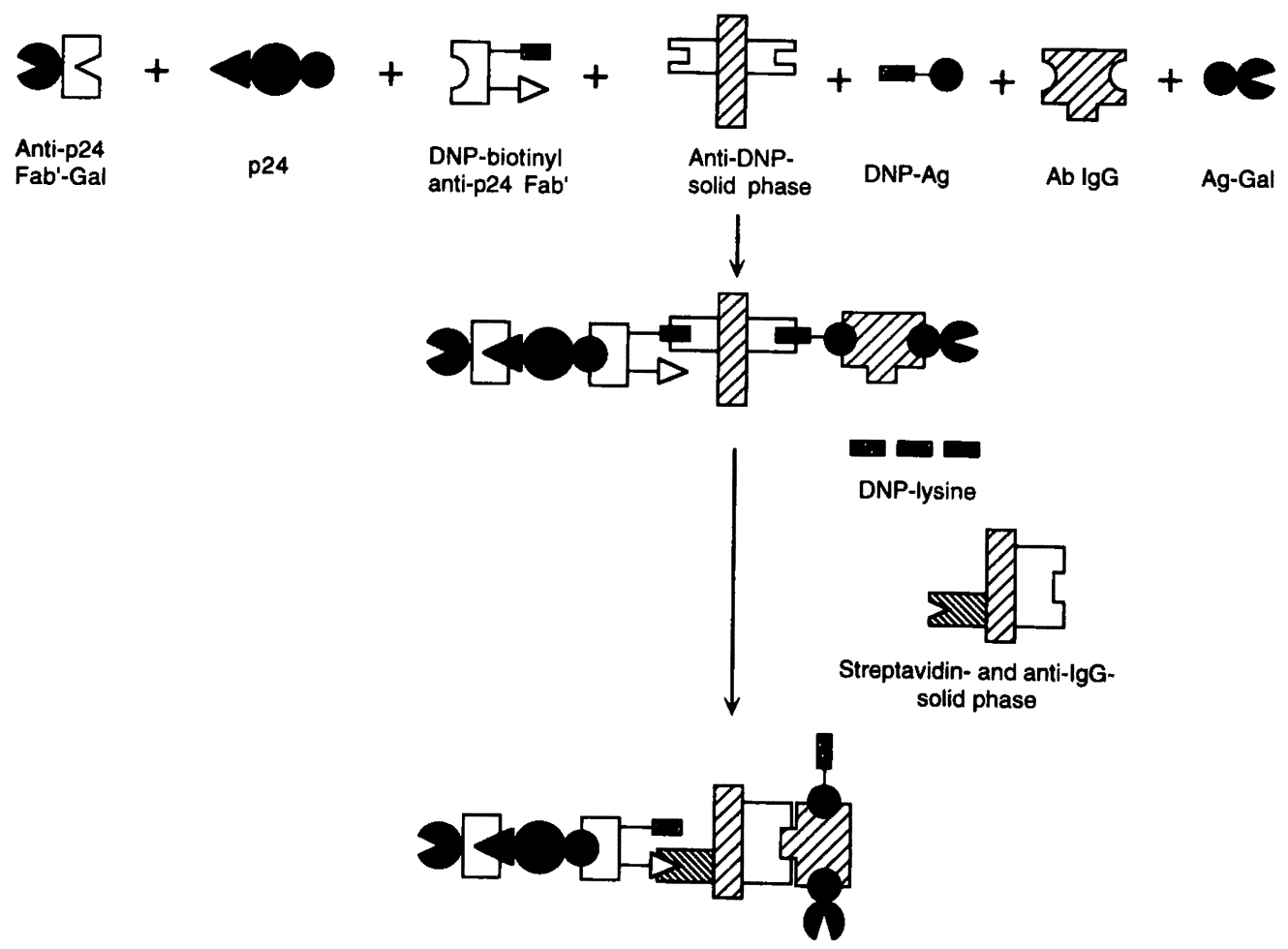

Fig. 6. Immune complex transfer enzyme immunoassay for simultaneous detection of both p24 antigen (left) and antibody IgG (right). DNP: 2,4-dinitrophenyl group, Ag: antigen, Ab: antibody, Gal: $\beta$-D-galactosidase. 


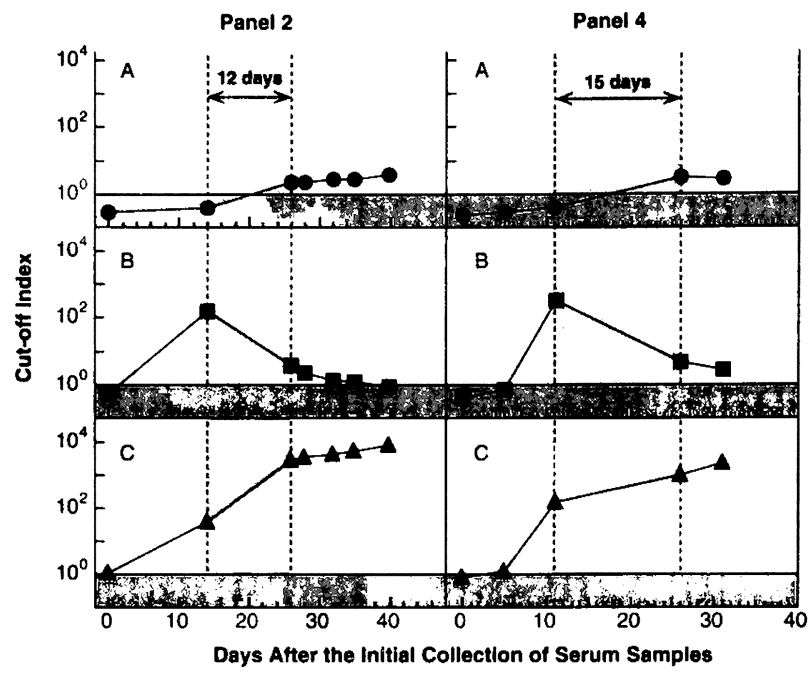

Fig. 7. Typical test results of seroconversion serum panels by the simultaneous detection shown in Fig. 6. Serum samples $(10 \mu \mathrm{l})$ of seroconversion serum panels were tested by the immune complex transfer enzyme immunoassay for simultaneous detection of both p24 antigen and antibody IgGs to RT and p17 using $\beta$-D-galactosidase from Escherichia coli as label. Bound $\beta$-D-galactosidase activity was assayed at $30^{\circ} \mathrm{C}$ for $2.5 \mathrm{hr}$. A: Abbott 3rd generation ELISA, B: Immune complex transfer enzyme immunoassay for p24 antigen, C: Simultaneous detection.

\section{Test of seroconversion serum panels}

On the basis of the above results and considerations, the immune complex transfer enzyme immunoassay for simultaneous detection of both p24 antigen and antibody IgGs to p17 and RT in a single assay tube has been developed (Fig. 6), and eleven HIV-1 seroconversion serum panels were tested (Fig. 7) [3, 6]. For detection of p24 antigen, monoclonal mouse anti-p24 Fab'- $\beta$-D-galactosidase conjugate was used. Signals by the simultaneous assay became positive 6 to 42 days earlier than those by conventional methods for antibodies to HIV-1 and remained strongly positive even after signals for p 24 antigen alone declined, although the cut-off indices by the simultaneous assay were lower than those for p24 antigen alone or for antibody IgG to $\mathrm{p} 17$ alone. In addition, 79 serum samples randomly collected from HIV-1 seropositive subjects (50 asymptomatic carriers, 9 patients with ARC and 20 patients with AIDS) were subjected to the simultaneous detection. The ratios of the lowest signals for the asymptomatic carriers and the patients with ARC and AIDS to the highest signal for $100 \mathrm{HIV}-1$ seronegative subjects were $69,000,199,000$ and 3,330 , respectively.

Thus, by the simultaneous detection of p24 antigen and antibody IgGs to p17 and RT with the immune complex transfer enzyme immunoassay, both as early a diagnosis of HIV-1 infection as the appearance of p24 antigen in the circulation to shorten "the window period" and as reliable a diagnosis of the infection as that by the detection of antibodies to HIV-1 from the time of seroconversion until late stages of the infection became possible.

\section{Improvement of Immune Complex Trans- fer Enzyme Immunoassay}

The immune complex transfer enzyme immunoassay described above has the following drawbacks. Polystyrene beads were transferred from test tubes to test tubes with tweezers, and tips of the tweezers had to be washed carefully after each transfer of polystyrene beads to eliminate the false-positivity due to carryover [10]. In addition, fluorescence intensities for bound enzyme activities of many samples were measured one by one with a spectrofluorophotometer. This was tedious and timeconsuming, making the assay of many samples difficult.

These drawbacks have been recently minimized by substituting microplates, a fluororeader and polystyrene sticks for test tubes, a spectrofluorophotometer and polystyrene beads, respectively $[2,12,13]$. Polystyrene sticks were transferred easily and quickly from wells to wells without using tweezers, eliminating false-positivity due to carryover. Fluorescence intensities of bound $\beta$-Dgalactosidase activities for 96 samples could be measured within one min and $40 \mathrm{sec}$ with a fluororeader. In addition, the sensitivity was also improved. Thus, many samples could be tested using polystyrene sticks, microplates and fluororeader much more easily with higher sensitivity and higher reliability.

Another drawback of the immune complex transfer enzyme immunoassay for antibody IgG to HIV-1 described above is requiring a long time for its performance. This has been also recently overcome [15]. The immune complex comprising 2,4-dinitrophenyl-bovine serum albumin-HIV-1 antigen conjugate, anti-HIV-1 IgG and HIV-1 antigen- $\beta$-D-galactosidase conjugate was trapped onto polystyrene beads coated with (anti-2,4-dinitrophenyl group) IgG by overnight incubation and was transferred to polystyrene beads coated with (anti-human IgG $\gamma$-chain) IgG by $3 \mathrm{hr}$ incubation in the presence of excess of $\varepsilon N-2,4$ dinitrophenyl-L-lysine. These processes were made efficient by incubation with shaking and by using solid phases with larger surface areas. In addition, the volume of serum samples used was increased from $10 \mu \mathrm{l}$ to $100 \mu \mathrm{l}$. As a result, the sensitivity was improved 20 to 30 -fold, even when both trapping and transferring of the immune complex were performed for only $30 \mathrm{~min}$. Furthermore, testing many samples became easily possible with higher sensitivity using microplates and a fluororeader.

With this improved immune complex transfer enzyme immunoassay for antibody IgG to p17 of HIV-1, 12 seroconversion panels were tested and antibody IgG to p17 was detected earlier than p24 antigen in four seroconversion serum panels of the 12 (to be published in detail elsewhere).

\section{References}

1. Constantine, N.T.: Serologic tests for the retroviruses: approaching a decade of evolution. AIDS. 7; 1-13, 1993. 
2. Hashida, S., Ishikawa, S., Nakamoto, H., Tanaka, S., Kojima, M. and Ishikawa, E.: Simple and more sensitive immune complex transfer enzyme immunoassay for antibody IgG to reverse transcriptase of HIV-1 using microplates, modified polystyrene solid phase, and fluororeader. J. Clin. Lab. Anal. 10; 294-301, 1996.

3. Hashida, S., Hashinaka, K., Nishikata, I., Saitoh, A., Takamizawa, A., Shinagawa, H. and Ishikawa, E.: Earlier diagnosis of HIV-1 infection by simultaneous detection of p24 antigen and antibody IgGs to p17 and reverse transcriptase in serum with enzyme immunoassay. J. Clin. Lab. Anal. 10; 213$219,1996$.

4. Hashida, S., Hashinaka, K., Nishikata, I., Saito, A., Takamizawa, A., Shinagawa, H. and Ishikawa, E.: Ultrasensitive and more specific enzyme immunoassay (immune complex transfer enzyme immunoassay) for p24 antigen of HIV-1 in serum using affinity-purified rabbit anti-p24 Fab' and monoclonal mouse anti-p24 Fab'. J. Clin. Lab. Anal. 10; 302307, 1996.

5. Hashida, S., Hashinaka, K., Nishikata, I., Oka, S., Shimada, K., Saitoh, A., Takamizawa, A., Shinagawa, H. and Ishikawa, E.: Measurement of human immunodeficiency virus type 1 p24 in serum by an ultrasensitive enzyme immunoassay, the two-site immune complex transfer enzyme immunoassay. J. Clin. Microbiol. 33; 298-303, 1995.

6. Hashida, S., Hashinaka, K., Nishikata, I., Oka, S., Shimada, K., Saitoh, A., Takamizawa, A., Shinagawa, H. and Ishikawa, E.: Shortening of the window period in diagnosis of HIV-1 infection by simultaneous detection of p24 antigen and antibody IgG to p17 and reverse transcriptase in serum with ultrasensitive enzyme immunoassay. J. Virol. Methods 62; 43-53, 1996.

7. Hashida, S., Hashinaka, K., Saitoh, A., Takamizawa, A., Shinagawa, H., Oka, S., Shimada, K., Hirota, K., Kohno, T., Ishikawa, S. and Ishikawa, E.: Diagnosis of HIV-1 infection by detection of antibody IgG to HIV-1 in urine with ultrasensitive enzyme immunoassay (immune complex transfer enzyme immunoassay) using recombinant proteins as antigens. J. Clin. Lab. Anal. 8; 237-246, 1994.

8. Hashida, S., Hashinaka, K., Nishikata, I., Oka, S., Shimada, K., Saitoh, A., Takamizawa, A., Shinagawa, H., Yano, S., Kojima, H., Izumi, T. and Ishikawa, E.: Immune complex transfer enzyme immunoassay that is more sensitive and specific than Western blotting for detection of antibody immunoglobulin $\mathrm{G}$ to human immunodeficiency virus type 1 in serum with recombinant pol and gag proteins as antigens. Clin. Diag. Lab. Immunol. 2; 535-541, 1995.

9. Ishikawa, E. and Kohno, T.: Development and applications of sensitive enzyme immunoassay for antibodies: A review. J. Clin. Lab. Anal. 3; 252-265, 1989.

10. Ishikawa, S., Hashida, S., Kohno, T. and Ishikawa, E.: Use of microplates and fluororeader for ultrasensitive enzyme immunoassay (immune complex transfer enzyme immunoassay) of anti-HTLV-I IgG. J. Clin. Lab. Anal. 8; 327-331, 1994.

11. Ishikawa, E., Hashida, S., Kohno, T., Hirota, K., Hashinaka, K. and Ishikawa, S.: Principle and applications of ultrasensitive enzyme immunoassay (immune complex transfer enzyme immunoassay) for antibodies in body fluids. J. Clin. Lab. Anal. 7; 376-393, 1993.

12. Ishikawa, S., Hashida, S., Nakamoto, H., Tanaka, S., Kojima, M. and Ishikawa, E.: Further simplification of ultrasensitive enzyme immunoassay (immune complex transfer enzyme immunoassay) for anti-HTLV-I IgG using microplates and fluororeader. J. Clin. Lab. Anal. 9; 204-211, 1995.

13. Ishikawa, S., Hashida, S., Nakamoto, H., Tanaka, S., Kojima, M. and Ishikawa, E.: Simpler and more sensitive immune complex transfer enzyme immunoassay for anti-HTLV-I IgG using modified polystyrene beads, microplates and fluororeader. Anal. Lett. 28; 1611-1618, 1995.

14. Ishikawa, S., Hashida, S., Hashinaka, K., Hirota, K., Saitoh, A., Takamizawa, A., Shinagawa, H., Oka, S., Shimada, K. and Ishikawa, E.: Diagnosis of HIV-1 infection with whole saliva by detection of antibody IgG to HIV-1 with ultrasensitive enzyme immunoassay using recombinant reverse transcriptase as antigen. J. Acquir. Immune Defic. Syndr. Human Retrovirol. 10; 41-47, 1995.

15. Ishikawa, S., Hashida, S., Hashinaka, K., Kojima, M., Saito, A., Takamizawa, A., Shinagawa, H., Oka, S., Shimada, K. and Ishikawa, E.: More sensitive immune complex transfer enzyme immunoassay for antibody IgG to p17 of HIV-1 with shorter incubation time for immunoreactions and larger volumes of serum samples. J. Clin. Lab. Anal. 1997. (in press)

16. Ishikawa, S., Hashida, S., Hashinaka, K., Hirota, K., Kojima, M., Saito, A., Takamizawa, A., Shinagawa, H., Oka, S., Shimada, K. and Ishikawa, E.: Whole saliva dried on filter paper for diagnosis of HIV-1 infection by detection of antibody IgG to HIV-1 with ultrasensitive enzyme immunoassay using recombinant reverse transcriptase as antigen. J. Clin. Lab. Anal. 10; 35-41, 1996. 